\title{
Maruja Mallo: artista, cronista, ¿surrealista?
}

\author{
Maruja Mallo: Artist, Chronicler, Surrealist?
}

\author{
Manuel FERNÁNDEZ LUCCIONI \\ Universidad Complutense de Madrid \\ manuferlu86@yahoo.es
}

[Recibido 16/01/2012, aceptado 25/04/2012]

\section{RESUMEN}

En este estudio nos preguntamos si desde la historiografía artística debería considerarse a Maruja Mallo como pintora surrealista y, si así fuera, si abarcaría la totalidad o una parte dentro de su obra. Asimismo, hacemos un repaso de su trayectoria hasta sus primeros trabajos en Latinoamérica.

PALABRaS ClaVE: Maruja Mallo, Surrealismo, André Bretón, Revista de Occidente, Verbenas, exilio, geometría, Dalí.

FERNÁNDEZ LuCCIONI, M. (2012): “Maruja Mallo: artista, cronista, ¿surrealista?”, Madrygal (Madr.), 15: 45-56.

\section{RESUMO}

Neste estudo preguntámonos se dende a historiografía artística debería considerarse Maruxa Mallo como pintora surrealista e, se así fose, se abarcaría a totalidade ou unha parte dentro da súa obra. Así mesmo, facemos un repaso da súa traxectoria ata os seus primeiros traballos en Latinoamérica.

Palabras ChaVe: Maruxa Mallo, Surrealismo, André Bretón, Revista de Occidente, Verbenas, exilio, xeometría, Dalí.

FERnÁNDEZ LuCCIONI, M. (2012): “Maruxa Mallo: artista, cronista, ¿surrealista?”, Madrygal (Madr.), 15: 45-56.

\section{ABSTRACT}

This article comes to wonder whether from Artistic History should be considered Maruja Mallo as a Surrealist painter, and if so would cover all or part of her work making overview of her career until her early works in Latin America.

KEY WORDS: Maruja Mallo, Surrealism, André Bretón, Revista de Occidente, Verbenas, exile, geometry, Dalí.

Fernández LuCCioni, M. (2012): "Maruja Mallo: "Maruja Mallo: Artist, Chronicler, Surrealist?”, Madrygal (Madr.), 15: 45-56.

SUMARIO: 1 . Introducción. 2. La formación, encumbramiento y expansión de la artista antes del exilio (19021937). 3. De los agricultores y los pescadores a las conchas y las flores: geometría en el exilio (1937-1944). 4. Conclusiones: ¿es surrealista Maruja Mallo? 5. Referencias bibliográficas. 


\section{INTRODUCCIÓN}

Habitualmente solemos utilizar la palabra $s u$ rrealismo o surrealista de forma muy vaga, más en concreto cuando hablamos de forma coloquial. Esto es lo que pasó con la figura de Maruja Mallo y otras tantas mujeres artistas en la España de principios del siglo XX. La inmersión de estas artistas que rompieron tantos moldes $-\mathrm{y}$ no solamente como artistas- en espacios que históricamente habían estado reservados a los hombres también ha hecho que su denominación de surrealistas, más allá de quedarse en una simplificación que nos hacía perder parte de la información, sirviera como elemento peyorativo, como un lugar común donde almacenar todo aquello que no podemos catalogar fácilmente.

Este estudio se adentra en el mundo de Maruja Mallo, en sus relaciones, en sus intereses y pasiones, de manera que podamos saber si realmente fue una pintora surrealista, o si debemos adscribir esta parte someramente a sus famosas Verbenas, o al ciclo Cloacas y Campanarios, tan alabado por André Breton y Paul Éluard. ¿Hasta qué punto está contaminada por estos acontecimientos del principio de su carrera -y otros que ocurrieron en su vida- la idea que tenemos hoy en día de Maruja Mallo?

Haciendo un breve repaso de las publicaciones sobre la artista, cabe decir que la figura de Maruja Mallo ha cobrado un especial interés para la historiografía española en los últimos años, sobre todo después de su fallecimiento en febrero de 1995.

Aunque la profesora García de Carpi le dedicase un apartado en su libro La pintura surrealista española (1924-1936) en 1986, y apareciese la excepcional aportación de Galdo en 1992, quien publicó la partida de nacimiento de la artista, no es hasta esa fecha cuando la figura de Maruja Mallo empezó a tenerse más en cuenta. Obviamente no podemos perder de vista la exposición homónima que el Centro de Arte Contemporánea de Santiago de Compostela le dedicó en 1993.

Las primeras publicaciones tras su muerte fueron los homenajes que tanto la profesora De Diego, como Soledad Ortega, hija del pensador Ortega y Gasset, quisieron rendirle desde la Revista de Occidente, con la cual Maruja Mallo había tenido una especial relación. Es especialmente interesante la aportación de la profesora De Diego, que ya se planteó entonces la conveniencia de circunscribir a la artista dentro del Surrealismo.
Tras estos primeros momentos hay un lapso en las publicaciones referidas a Maruja Mallo, de manera que hasta el 2002 no volvemos a encontrar ningún otro texto significativo. Será en ese año cuando vuelvan a aparecer con fuerza pequeñas revisiones sobre la artista, como la exposición organizada en la Galería Guillermo García de Osma de Madrid llamada Naturalezas vivas, donde se estudiaron las primeras obras de la artista en Latinoamérica, el libro colectivo Creadores del Arte Nuevo, que incluye una pequeña monografía realizada por Pérez de Ayala (quien también se hizo cargo del catálogo de la exposición anteriormente comentada) y un artículo de López López en la revista Madrygal, en la que se incide en la clara vinculación de esta etapa con los libros clásicos de geometría.

Ya en 2004 se publicó la mejor monografía que podemos encontrar sobre la artista, escrita por Ferris y llamada Maruja Mallo, La gran transgresora del 27, que trata tanto la vida como la obra de la artista gallega. Igualmente importante para el estudio de Maruja Mallo y otras mujeres artistas españolas de principios del siglo XX es la tesis doctoral de Rodríguez Calatayud: Archivo y memoria femenina. Los textos de la mujer artista durante las primeras vanguaridas (1900-1945), leída en el año 2007, ya que nos completa ampliamente la investigación aportando multitud de fuentes primarias; son particularmente interesantes aquellas en las que interviene la propia artista.

Por último, cabe señalar dos textos más. La monografía homónima que le dedicó la profesora De Diego en el año 2008 y la última exposición antológica que se celebró en el 2010 en la Academia de San Fernando, también con el nombre Maruja Mallo.

\section{FORMACIÓN, ENCUMBRAMIENTO Y EXPANSIÓN DE LA ARTISTA ANTES DEL EXILIO (1902-1937)}

Maruja Mallo nunca fue sincera con su edad. Los historiadores siempre dieron por bueno que había nacido en Tui en 1909, testimonio que no se puso en duda hasta que Galdo sacó a la luz su partida de nacimiento:

Ana María Manuela Isabel Josefa Gómez y González nació en Viveiro en la calle de Porlier, antigua calle del Sol, hoy Avenida de Lourdes, el día cinco de Enero de 1902, a la una de la tarde, 
hija legítima de D. Justo Gómez Mallo, administrador de Aduanas, natural de Madrid y de su esposa D. ${ }^{a}$ María González Lorenzo dedicada a sus labores, natural de Vigo, según consta en el Registro Civil inscrita con el n. ${ }^{\circ} 130$, folio ciento treinta y dos por el Juez Municipal D. Manuel Froilán Vilar. (Galdo 1992: 93)

Entre los testimonios que he leído de Maruja Mallo no he encontrado, sin embargo, ninguno en que afirmase que había nacido en ese año, ni ningún otro que permitiera deducir cuándo nació. Presumiblemente cabe pensar que esto lo empezó a decir cuando, llegada a América, comenzó a crearse un personaje que le acompañaría fielmente el resto de su vida. Hecho que, por otra parte, hacía más asombrosa una realidad ya de por sí deslumbrante: el que Ortega y Gasset hubiera decidido apadrinarla para realizar la única exposición que acogió la Revista de Occidente en toda su historia, en mayo de 1928.

Ahora sabemos, por tanto, que Maruja nació en Viveiro en 1902, pero también que pronto se marchó a vivir con sus tíos a Corcubión (Asturias), donde con poca edad demostrará sus habilidades para el dibujo y la pintura. Sin embargo, la primera noticia publicada que tenemos respecto de su producción artística es la exposición individual que hizo en Avilés en 1922, presentando 14 obras de corte academicista donde ya demostraba la buena mano que poseía.

Ese mismo año se trasladó junto con su familia a vivir a Madrid, y tanto ella como su hermano Cristino -que sería después un escultor de renombre- ingresaron en la Academia de Bellas Artes de San Fernando. Allí Maruja conoció a Salvador Dalí, quien la pondría en relación con Federico García Lorca, Luis Buñuel y la Residencia de Estudiantes, dirigida entonces por Alberto Jiménez Fraud.

Si bien Maruja Mallo estuvo desde 1924 apuntada a clases de dibujo libre en la escuela que tenía el pintor Julio Moisés en el Paseo de la Alhambra, la principal actividad de su juventud en Madrid se dio con sus amigos de la Residencia de Estudiantes y con Margarita Mansó, quien también estudiaba en la Academia de Bellas Artes. Con esta última, Dalí y Lorca protagonizarían varias chiquilladas que junto con otras locuras de la propia artista le dieron a Maruja Mallo una imagen de mujer extravagante. Es el caso de su "travestismo a la inversa" realizado junto a Mansó con las chaquetas de Dalí y Lorca para que las dejaran entrar en el Monasterio de Silos, o el momento en el que los cuatro amigos decidieron entrar en la Plaza Mayor sin sombrero, para acabar siendo insultados y apedreados por falta de decoro.

Maruja terminará sus estudios en la Academia de Bellas Artes en 1926 tras haber intentado participar en dos exposiciones de arte gallego celebradas en Compostela en 1923 y 1926. Para su desgracia, ese año falleció su madre, motivo por el que acompañó a su padre unos meses a Gran Canaria, donde pintará su célebre La isleña. Es en este tiempo, entre 1926-27, cuando comenzará a pintar los cuadros deportivos inspirados en su amistad con Concha Méndez ${ }^{1}$, los de verbenas, y también las estampas, que presentaría en agosto de 1927 en el Pabellón de la Feria de Muestras de Gijón y que gozarían de una gran acogida en varios artículos de periódicos locales, como los de Díaz Fernández (El Noreste, 21/08/1927) y Pestaña Nóbrega (La rosa de los vientos, 01/1928).

Con este breve bagaje Maruja abrió las puertas de su casa al periodista De Valdeavellano, quien publicó un artículo muy elogioso sobre esta prometedora artista (La Gaceta Literaria, 01/09/1927), en la revista de arte que había fundado Jiménez Caballero $^{2}$ y en la que escribía quien sería uno de sus grandes amigos y valedores, Ramón Gómez de la Serna. Esta conexión con Gómez de la Serna, nos puede hacer pensar en su extraordinaria aparición en la sede de la Revista de Occidente -como veremos más adelante-, en cuyas tertulias participaba Don Ramón junto con las mentes más privilegiadas de la España de entonces, como Gregorio Marañón, Pérez de Ayala, Fernando Vela, o el mismísimo Ortega y Gasset, fundador de la revista. En cualquier caso, su éxito no parece algo casual.

La hija del pensador, Soledad Ortega, relató muchos años después cómo fue la llegada de esta "gallega, menuda, de facciones muy acusadas y ojos agudos y brillantes" a la sede de la revista (Ortega 1995: 75). En este texto, la autora hace

\footnotetext{
1 Resultan interesantes unos testimonios de Concha Méndez sobre su amistad juvenil con Maruja Mallo (Ulacia Altoaguirre 1990: 51-52, apud. Pérez de Ayala 2002a: 372).

2 Jiménez Caballero presentará una de las cuatro Verbenas de Maruja Mallo en su reportaje documental Esencia de Verbena (1928) y en 1939 cambiará drásticamente su opinión sobre la artista en un artículo publicado en la revista Levante (28/07/1939).
} 
notar que a la chica atrevida que traía consigo unos bocetos para ilustrar la publicación no solamente le sorprendió que le fueran aceptados, sino que además le propusieran realizar una exposición sobre su obra. No obstante, esta versión contrasta con la que escribió la propia Maruja Mallo en 1979 -dieciséis años antes que Ortega-, en la que comenta que, siendo estudiante, fue llamada por Ortega y Gasset para conocerla, y que cuando este vio lo que había pintado en su casa -la de Maruja-, decidió inmediatamente abrirle las puertas de los salones de la revista para que expusiera allí su obra (Rodríguez Calatayud 2007: 555).

No tenemos información alguna que desacredite la primera versión de Ortega, mientras que en el caso de lo dicho por Maruja Mallo cabe recordar que por entonces ella llevaba mucho tiempo tergiversando la fecha de su nacimiento. La confusión sobre su edad está vinculada a esta primera gran exposición individual, de forma que entre la finalización de sus estudios en la Academia de Bellas Artes y la exposición de Revista de Occidente pasaron casi dos años, por lo que resulta complicado creer la explicación de Maruja. Sea como fuere, la carrera de Maruja Mallo despegó esplendorosamente tras esta extraordinaria exposición, que tiene más valor aún si pensamos que fue la única que la Revista de Occidente realizó en toda su historia. Allí expuso diez cuadros y treinta estampas, que fueron la delicia de la crítica especializada de la época -encarnada por Manuel Abril, Francisco Alcántara y Antonio Espina principalmente-, que agasajó a la joven pintora con grandes elogios. Fueron especialmente celebradas sus muy coloristas Verbenas, con las que traspuso al lienzo las fiestas de Madrid, bien sazonadas de un sarcasmo que con el tiempo se ha puesto cada vez más de relieve, si bien su éxito con las estampas no se quedaría atrás; sobre todo para las revistas de vanguardia (Revista Avance, 15/08/1928).

Tras ello, al tiempo que realiza la portada del libro de Jiménez Caballero Yo, inspector de alcantarillas, conoce a Benito Palencia y a Alberto Sánchez, fundadores de la Escuela de Vallecas, con quienes pasearía por el cerro de Vallecas en varias ocasiones (Rodríguez Calatayud 2007: 556-557), descubriendo el contraste que producían la basura y la podredumbre de los arrabales del Madrid de entonces si se com- paraban con el bullicioso Madrid castizo. En ese período realizaría también excursiones por los pueblos de Castilla La Nueva junto con Miguel Hernández.

Tras esta primera etapa, su paleta de colores tan viva se oscureció quedándose únicamente el blanco, el negro y el marrón. Con ellos realizará su ciclo denominado Cloacas y campanarios -título tomado de la exposición que hará en la Galerie Pierre Loeb de París en 1932-, en el que destaca la ausencia de la figura humana y donde predominan el esqueleto, el andrajo o la huella.

Estas obras están muy ligadas a Rafael Alberti, cuya producción también se oscureció tras ganar el Premio Nacional de Poesía en 1925 con Marinero en tierra, lo que constituyó una pérdida para la poesía de la que Juan Ramón Jiménez hizo responsables a Salvador Dalí y a la propia Maruja Mallo (La Gaceta Literaria, 15/01/1931). Es, a su vez, el momento en el que realizará junto con su hermano Justo las célebres fotografías de Cercedilla en el verano de $1929^{3}$, en las que se encuentran referencias a la muerte. También en ese año solventó su deuda con la Diputación de Lugo, que la había becado en varias ocasiones en su juventud, depositando la obra Guía postal de Lugo en la que, a modo de collage, nos presenta los elementos más característicos de la ciudad (Galdo 1992: 95).

Ya al principio de la siguiente década, Maruja Mallo entrará de nuevo en la órbita de Ortega y Gasset, realizando ilustraciones para la Revista de Occidente durante 1931-33, tiempo entre el cual pasará unos meses en París becada por la Junta para la Ampliación de Estudios de Madrid. La noticia de su viaje aparece publicada en una entrevista realizada por Josefina Carabias, en la que la periodista se muestra extrañada por el brusco cambio de estética que Maruja había dado en su obra (Estampa, 14/11/1931). A ella le cuenta que el objetivo del viaje es aprender escenografía, algo que ya había empezado a interesarle en el año 1930, cuando realizó los decorados de Santa Casilda, obra dramática de Rafael Alberti. Será Pérez de Ayala quien nos informe de su contacto durante su estancia parisina con los hermanos Jean y Valentine Hugo (Pérez de Ayala 2002b: 379), que habían trabajado en los decorados y los vestuarios de La passion de Jeanne d'Arc de Dreyer. Pese a todo ello, la estancia allí dependía

\footnotetext{
3 Al igual que ocurrirá con las fotografías que se hizo con Pablo Neruda en la Isla de Pascua, Maruja Mallo las compondrá a su gusto - en las segundas incluso retocará el resultado de la fotografía.
} 
de cuánto tiempo le llevase alcanzar su objetivo principal: exponer en la capital francesa.

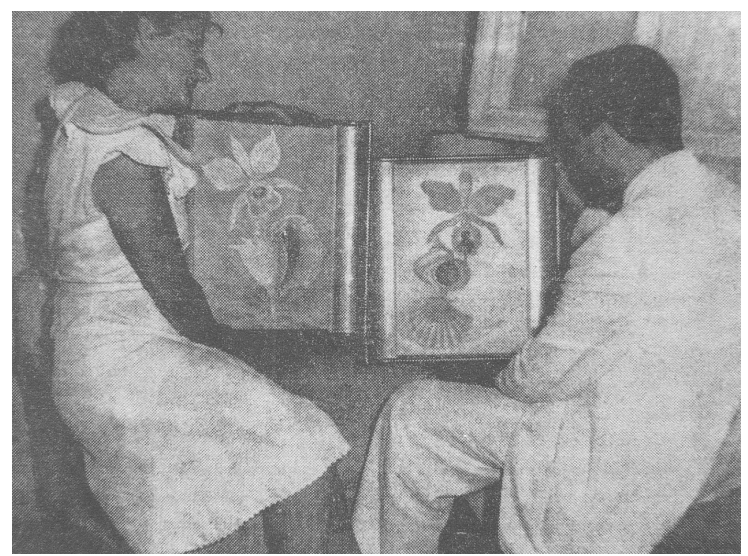

Figura 1. Maruja Mallo en el Hotel Copacaban, Brasil, 1946 (Pérez de Ayala 2002b: 28).

En este sentido podemos considerar que Maruja Mallo realizaba dos tipos de exposiciones. Por una parte es evidente que hacía muestras privadas, si no ya en su propia casa de Madrid, sí en las habitaciones de los hoteles donde residía -esto es más evidente en la etapa americana (figura 1). De este modo fue descubierta y vendió varias de sus obras. Y por otra parte, estaban las exposiciones propiamente dichas, en galerías de arte o en salones privados, como lo ocurrido con Revista de Occidente.

Así ocurrió en París en el año 1932, donde primero mostró su obra al líder de los surrealistas, André Breton y a su compañero Paul Éluard, y al estar ellos encantados ${ }^{4}$ logró el contacto con la Galeríe Pierre Loeb. Fue en esta galería donde se dio a conocer la obra de Joan Miró, que también tenía a la venta varios cuadros de Picasso y, aún más importante, era donde se había celebrado en 1925 la primera exposición de los surrealistas como grupo. La profesora García de Carpi relaciona esta exposición con Las dos Castillas, el libro que escribió Gutiérrez Solana en 1925, por sus descripciones de la carroña y los esqueletos de animales muertos del cementerio de Colmenar Viejo (1986: 171).

A pesar de todo, poca información tenemos sobre la estancia de Maruja Mallo en París, donde apenas estuvo unos meses, regresando a España pese a la propuesta de contrato que recibió de
Paul Rosemberg, como ella misma les contó a Amón y Bonet en el año 1977 (El País, 30/01/1977). A su vuelta a Madrid, su mentalidad había cambiado, lo que le lleva incluso a renegar de sus dos primeras exposiciones en una entrevista que realizó en Argentina en 1939 (Rodríguez Calatayud 2007: 524-530). Maruja entra en contacto con el grupo de Arte Constructivo, liderado por Joaquín Torres-García y se centra mucho más en el estudio de las formas de la naturaleza a través de la geometría. En ese sentido acude a las fuentes bibliográficas clásicas, como La Divina Proporción de Luca Pacioli (López López 2002: 83) o El número de oro de Matica $\mathrm{C}$. Ghyka. A ello hay que sumarle sus conocimientos de escenografía adquiridos en París y su novedoso uso de materiales pobres, como nos cuenta Pablo Neruda, a quien conoció en su Casa de las flores en 1934:

Nos íbamos con Maruja Mallo, la pintora gallega por los barrios bajos, por las casas donde vendían esparto y esteras, buscando las casas de los toneleros, de los cordeleros, de todas las materias secas de España, materias que trenzan y agarrotan su corazón. (Neruda 1974: 128)

Con todo, no podemos dejar de lado un hecho que será trascendental para Maruja Mallo, el fallecimiento de su padre en 1933 (Ferris 2004: 92), lo que además de provocar una gran conmoción, supuso una grave pérdida de autonomía al no tener el respaldo económico que este le procuraba, pues lejos de haber sido un cercenador de vocaciones, apoyó a sus dos hijos en todo lo que pudo. Por este motivo, Maruja Mallo tuvo que renunciar en parte a París y a su carrera artística, opositando a la cátedra de Dibujo y aceptando como destino el Instituto de Arévalo. Sin embargo, esta nueva etapa como docente no interrumpiría su actividad anterior, como demuestra su participación como artista invitada en la Escuela de Cerámica de Madrid para la que hizo diseños geométricos.

Sus trabajos heterodoxos en lo material -que dieron lugar a escenografías, cerámicas y dibujos-, pero aunados en un ideal geométrico (figura 2), fueron presentados en la exposición celebrada en mayo de 1936 en la sede madrileña del A.D.L.A.N. (Amigos de las Artes Nuevas), en la Carrera de San Jerónimo, organizada por Blanco

\footnotetext{
${ }^{4}$ Breton le compró El espantapájaros y Éluard quiso comprarle Grajo y excrementos, pero no pudo porque no podía pagarlo.
} 
Soler, Ángel Ferrant y Guillermo de Torre, con quien había colaborado haciendo viñetas en el Almanaque literario en el año anterior.

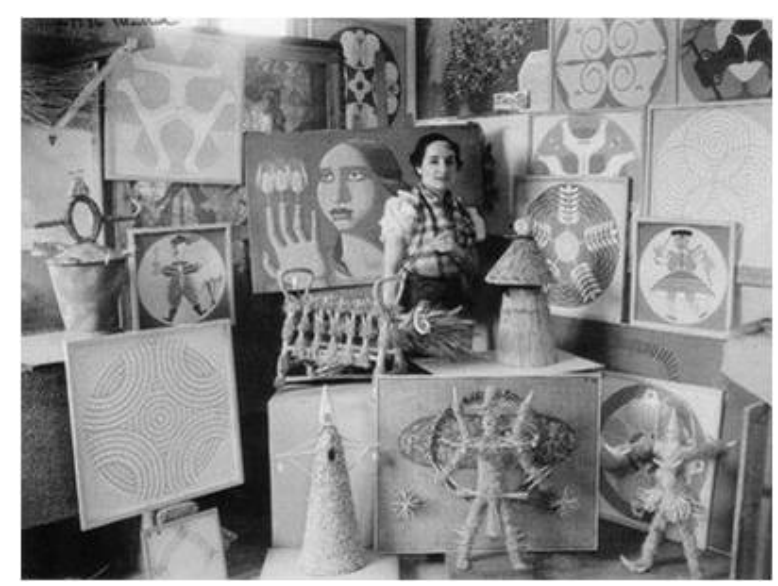

Figura 2. Maruja Mallo en su estudio, Madrid, 1936. Archivo Maruja Mallo, Galería Guillermo de Osma, Madrid (Diego de Otero 2008: 123).

En esta última exposición madrileña antes de su exilio, Maruja Mallo presentó los 16 dibujos de Construcciones rurales realizados durante 19331935 y las cerámicas que hizo en la Escuela de Cerámica de Madrid en las que se hace eco de sus nuevas tendencias, todo ello destruido durante la Guerra Civil. No faltaron tampoco los figurines y las maquetas que realizó con Rodolfo Halffter para el musical Clavileño -basado en El Quijote-, y que se estrenó en el salón de actos de la Residencia de Estudiantes en otoño de ese mismo año, así como el cuadro La sorpresa del trigo ${ }^{5}$, que presidió la muestra, y que contiene ya el germen de su futuro ciclo titulado La religión del trabajo, que completará en Argentina entre 1937-1939.

La muestra fue mal acogida en su momento por la crítica contemporánea, como demuestran los comentarios de autores como Fornet (Estampa, 24/03/1934), quien señaló que la progresión de Maruja Mallo se había interrumpido en seco al estar descentrada atendiendo a las clases que impartía a los niños de la escuela de Arévalo.

Tras esta última exposición individual en Madrid enviará dos obras a la Exposición Lógicofobista de Barcelona, y participará también en la Exposición Internacional del Surrealismo celebrada en las New Burlington Galleries de
Londres (García de Carpi 1986: 166), se vinculará a las Misiones Pedagógicas y se marchará a Vigo, donde se hallará cuando ese verano de 1936 estalle la Guerra Civil Española. Pero antes de partir al exilio, Maruja Mallo realizó dibujos geométricos de pescadores en su famoso Cuaderno de Galicia, claramente relacionado con la pintura de su etapa argentina.

\section{DE LOS AGRICULTORES Y LOS PES- CADORES A LAS CONCHAS Y LAS FLO- RES: GEOMETRÍA EN EL EXILIO (1937-1944)}

Maruja Mallo llegó al puerto de Buenos Aires el 9 de febrero de 1937 en el Alcántara, barco que había tomado en Lisboa gracias al salvoconducto que le había ofrecido su amiga y embajadora chilena en la ciudad, Gabriela Mistral. Ella misma será también quien le organice el viaje a Uruguay y a Argentina, donde dará dos conferencias, invitada por las respectivas Asociaciones de Amigos del Arte (Pérez de Ayala 2002b: 282). Fue muy bien acogida por la sociedad argentina y por viejos amigos que vivían en el exilio, como Ramón Gómez de la Serna. En una entrevista muchos años después de su regreso a España, relató el excelente recibimiento que había tenido en América: “[...] hay que agradecer a estos países lo bien que nos recibieron. Nos consideraron europeos y ocupamos una situación superior a la que conocíamos en España" (El Pais, 30/01/1977).

La intención de Maruja Mallo fue escapar de las masacres que la guerra estaba produciendo en Galicia -Tui fue uno de los enclaves más afectados dentro de la región (La Vanguardia, 14/08/1938)-, así como volver a España cuando la República venciera la guerra, pero esa situación nunca se produjo y tuvo que aceptar que el exilio iba a ser mucho más prolongado de lo que podría haber imaginado en un primer momento. Sin embargo, hasta entonces encontramos a una Maruja Mallo que con la serie de La religión del trabajo está mandando un mensaje mucho más profundo de lo que se ha estudiado habitualmente, si bien algunos autores han sabido ver esta faceta del trabajo, y es Pérez de Ayala el primero en apuntar la existencia de un trasfondo político en la

\footnotetext{
5 Esta obra surgió al presenciar Maruja Mallo junto a María Zambrano una manifestación agrícola el 1 de mayo de 1936 , en la que quedó conmocionada ante un pan de medidas desproporcionadas que le presentó uno de los agricultores que se manifestaban para que mejorasen las condiciones de trabajo en el campo.
} 
obra de Maruja Mallo: “[...] son cuadros de gran poder plástico, de enorme fuerza iconográfica y de profunda carga humana con algo de política: no hay que olvidarse de que están pintados mientras España sufre los horrores de una guerra civil" (2002: 382).

Prosiguiendo con esta idea, si leemos los testimonios que publicó el 14, 16 y 21 de agosto de 1938 en el periódico La Vanguardia bajo el nombre de "Relato veraz de la realidad de Galicia"6, se nos hace evidente la denuncia que hace del engaño, asesinato colectivo y humillación -en este orden se describen en los artículos- que los nacionales llevaron a cabo en Galicia contra los agricultores y los pescadores, el tipo de gente que con mucho esfuerzo ayudó a construir un país:

Las carreteras y los pueblos de Galicia, antes del 18 de julio estaban repletos de campesinos que transitaban cargados de trigo y leña y de marineros que poblaban las playas inundándolas de redes y peces, cantando sus romances populares y sus canciones improvisadas. Ese mismo pueblo no canta ya. Claman justicia por las carreteras y por las riberas grupos de mujeres y niños desamparados. Galopan hacia los montes los hombres perseguidos como perros, por la fiera agresión de los falangistas, por la brutal cacería de los nacionalistas que disparan ante la personalidad humana. ( $L a$ Vanguardia, 14/08/1938)

Y ello podemos ponerlo en relación con la idea que la artista tiene del arte popular, así como del contemporáneo.

Otra fuente primaria que podemos aducir sobre la artista es el libro publicado por la Editorial Losada en Argentina (1939), donde se transcriben dos conferencias que Maruja había dado en América, acompañados de un interesante prólogo de Ramón Gómez de la Serna (Rodríguez Calatayud 2007: 537-547):

El arte popular es la representación lírica de la fuerza creadora del hombre, del poder de edificación del pueblo que construye cosas de proporciones, formas y colores inventados: creaciones mágicas de medidas exactas.

Por su parte De la Gándara, primera historiadora que estudió la producción de Maruja Mallo, sacó a la luz la preocupación de la artista por el proletariado en Arquitectura humana, Estrella de

\section{Mar (1937), El mensaje del mar y La red (1938):}

[...] su exaltada atención a las gentes sencillas que luchan en la era con las espigas, hoces, trillos y gavillas o a los marineros que lanzan las redes en la oscuridad de la noche y recogen con sudor las maromas. Estos elementos estilizados, convertidos en símbolo, constituyen el ámbito sobre el que se destacan los oficiantes del gran rito del mar o de la tierra. (Gándara 1976: 15)

En estas obras encontramos una vuelta a la figuración tras trabajos como sus Verbenas, que tanto éxito le habían reportado en Madrid. Sin embargo, ahora ya no nos hallamos ante figuras, sino ante construcciones basadas en la geometría. Buen ejemplo de ello es la obra con la que cierra la serie, El canto de las espigas (1939), en la que tres figuras a modo de orantes están rodeadas por espigas. En cierto modo no deja de ser la evolución de lo ya reflejado en el inicio de la serie, $L a$ sorpresa del trigo, 1936. Este cuadro, junto al final de la Guerra Civil, marcan un punto de inflexión en la trayectoria de Maruja Mallo, que tiene que hacerse a la idea de que América va a ser su destino a largo plazo.

Tras la desconexión con España (salvo alguna ligera vuelta a su pasado como es la participación en Cantata en la tumba de Federico García Lorca, drama de Alfonso Reyes, estrenada en abril de 1939, y donde realizó la escenografía), Maruja Mallo se dedicó a adaptarse a su nuevo entorno, un continente en el que encontró una segunda casa para las siguientes dos décadas y media. Durante estos años le impactó el paisaje que encontró en América: el colorido y la exuberancia vegetal que se daban allí sólo podían tener un leve eco en la experiencia que había tenido en las Islas Canarias más de diez años antes.

Aunque sensible al paisaje natural como en su primera juventud, ahora nos encontramos ante una Maruja Mallo con una nueva mentalidad: la del predominio de la geometría, factor ordenador y creador del mundo sobre todas las cosas, lo cual le llevaría incluso a medir las conchas que recolectaba en las playas americanas para después trasladarlas al lienzo.

La orientación que tomará la pintura de Maruja Mallo de estos momentos se centrará, por tanto, en la naturaleza, en los colores y las luces tan brillantes y nuevas para ella; pero, pese a ello,

\footnotetext{
${ }^{6}$ Este texto no fue publicado por completo, porque quedó cortado en la última entrega y posteriormente no se volvió a aludir a ello.
} 
su tendencia ya no cambiaría una vez conocido a Torres García y a su grupo constructivista en Madrid. La pintura de Maruja Mallo estaba hecha desde la razón, no desde la pasión.

Resulta paradójico ver cómo ella neutralizó con la geometría aquel mar de sensaciones que tanto la impresionó. Se rindió ante la naturaleza, pero no del todo, porque quiso aprehenderla, racionalizarla, hacerla suya. Responderá a un tipo de pintura pensada para sentir, pero no para apasionarse. No estamos hablando de emociones, no hablamos de expresividad, sino de la cumbre de lo racional, que es la síntesis, la simplificación, lo abstracto. Hablará del proceso biológico del cuadro, tomando como elementos básicos la forma, el color y la materia:

La forma, el color y la materia, constituyen allí [en la obra] una armonía dialogante, viviente, donde la ley y el contenido integran una totalidad, una unidad. Esas leyes que rigen mi pintura le dan su carácter universal. Aspiro a que los temas también sean universales. (Rodríguez Calatayud 2007: 524-530)

En estas dos décadas, Maruja Mallo se dejará llevar mucho por su experiencia en las playas de Punta del Este o de Valparaíso, donde tomará para sí lo que devuelve el mar, entre otras cosas, conchas enormes, las más bellas que jamás había visto. Los colores y diseños exóticos entrarán en su imaginario, ya de por sí muy personal.

El mar le dio todo lo necesario para poder hacer sus Naturalezas vivas (figuras 3 y 4), contraposi-

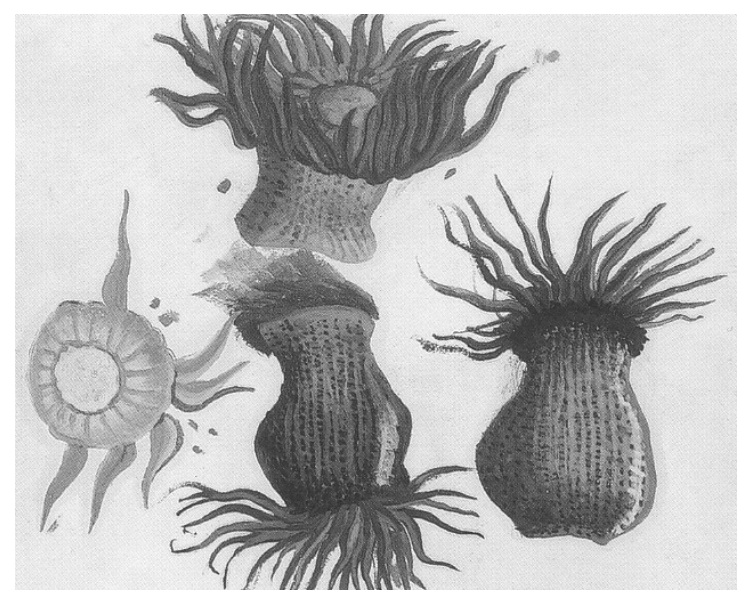

Figura 3. Algas, Febrero 1943 (Pérez de Ayala 2002b: 42).

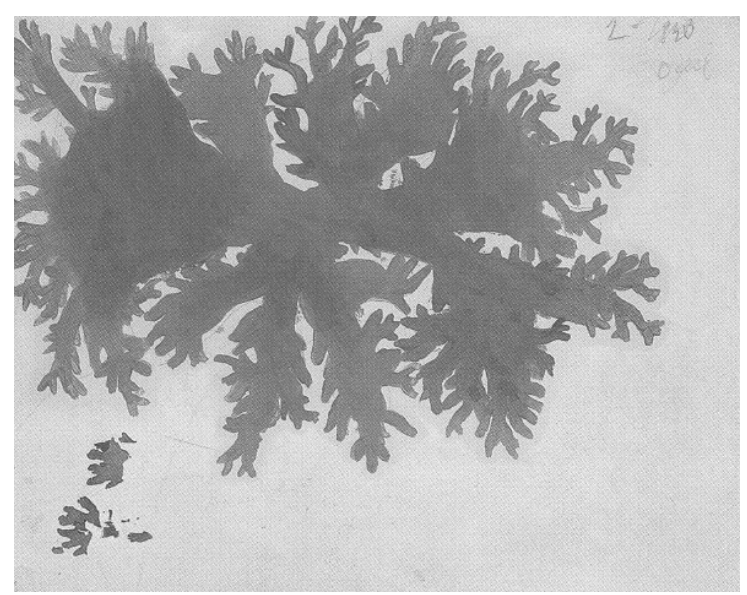

Figura 4. Algas, Febrero 1943 (Pérez de Ayala 2002b: 46).

ción de las naturalezas muertas, género tan valorado del Barroco español, donde hallamos ejemplos como los de Valdés Leal o Sánchez Cotán. Esto nos lleva a pensar que, si las naturalezas muertas o vanitas son una reflexión sobre el paso del tiempo y la fugacidad de la vida, ¿la idea de naturaleza viva podría llevarnos entonces a la plasmación de lo eterno y universal?, ¿a formas, texturas, colores y materias fijados para siempre en la imaginería de las sociedades occidentales?

La plástica de estas Naturalezas vivas nos dice que así es. Maruja Mallo buscaba reconocer las

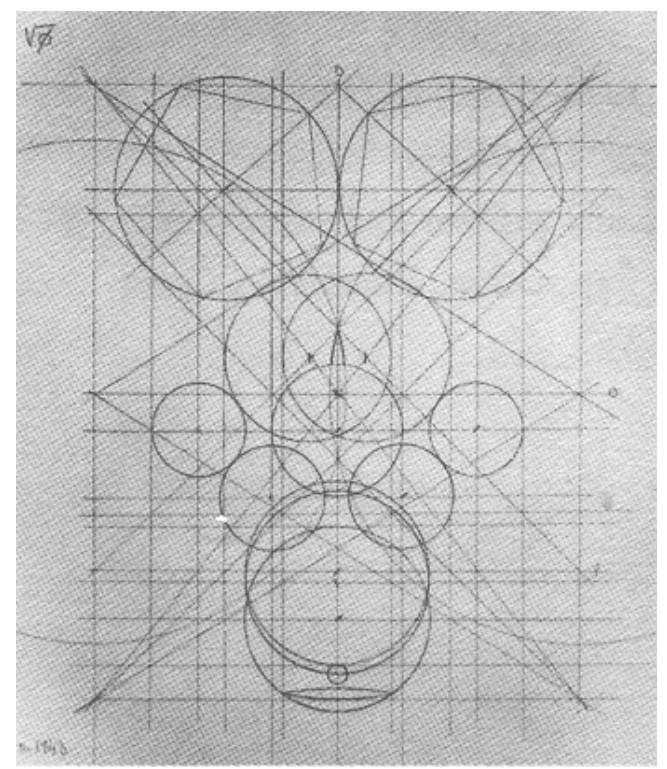

Figura 5. Trazado armónico, 1943 (Pérez de Ayala 2002b: 49). 


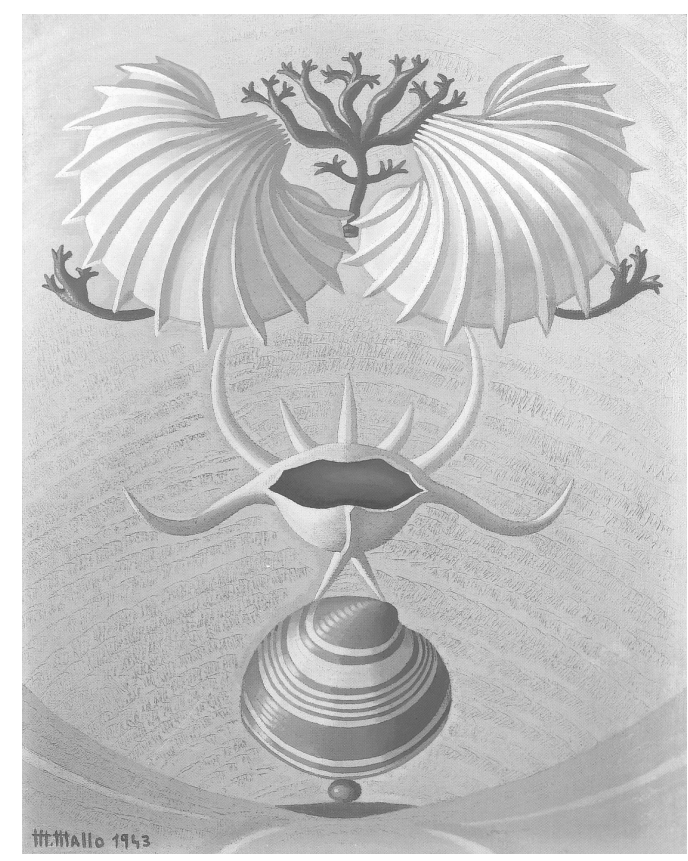

Figura 6. Naturaleza viva, 1943 (Pérez de Ayala 2002b: 66)

formas universales o la matriz en los objetos de la naturaleza para trabajar de maneras diferentes sobre ello (figuras 5 y 6). Ella se sirvió de esta herramienta para racionalizar o asimilar aquella fauna y vergel tan sorprendente:

Me maravillaba de vuestras playas. Las había azules, doradas, blancas. Las miraba y no lo creía. Me frotaba los ojos temiendo ver desaparecer la ilusión; pero permanecían y eran realidad. Y luego, las caracolas: ¡qué profusión de belleza, qué armonía de formas, qué deslumbradora arquitectura de acabada geometría! (Pérez de Ayala 2002a: 387)

Otro punto de vista interesante y complementario para estas Naturalezas vivas es su evidente carácter erótico (López López 2002: 84). Por no caer en ingenuidades, no es descabellado pensar que las conchas de Maruja Mallo causaran revuelo en Argentina en aquellos años a tenor de su significado sexual, como tampoco podemos desviar la mirada hacia las connotaciones que desde la pintura de Georgia O'Keefe adquirieron las pinturas de flores en el arte americano. Por ello, si a las conchas le sumamos las flores, un cuadro que a simple vista no pasaría de decorativo, con una lectura dirigida como la que acabamos de hacer, podría darnos obras manifiestamente sexuales; en cualquier caso, una visión muy adelantada, en su época, para una mujer artista.
Tras ello trabajará en las series de las Máscaras y de los Retratos bidimensionales -realizados por parejas-, retomando en la primera de ellas los fondos de mar y playa de esta última obra de las Naturalezas vivas y en la segunda las figuraciones constructivas de La religión del trabajo, pero con un sentido mucho más corpóreo. No deja de resultar llamativo que Maruja Mallo decidiese terminar la serie de las Naturalezas vivas, que había estado basada en los frutos y los animales del mar, o con obras como El racimo de uvas, que evoca claramente un pubis femenino.

\section{CONCLUSIONES: ¿ES SURREALISTA MARUJA MALLO?}

En principio esta es una cuestión que no ha lugar tratándose de una persona que fue reconocida por André Breton, el gran pope del grupo surrealista (quien le llegó a comprar El espantapájaros en 1932), y que hubo recibido los elogios de Paul Éluard, como reconoció años después Maruja Mallo en la entrevista realizada por Amón y Bonet.

Si a eso le añadimos las múltiples aventuras "surrealistas" que la propia Maruja Mallo se encargó de difundir en las entrevistas que le hicieron a uno y otro lado del Atlántico durante más de cuarenta años, no es procedente preguntarse si es o no surrealista porque queda patente que así lo es. No obstante, ¿es suficiente el reconocimiento de André Breton y las actitudes, en ocasiones, excéntricas de Maruja Mallo para catalogarla como una artista surrealista?

En ese sentido, resulta muy acertada la idea planteada por Estrella de Diego en un artículo sobre la artista publicado en Revista de Occidente: "Entonces, ¿llamamos a Mallo surrealista porque pintaba asuntos "surrealistas», porque era amiga de los surrealistas o porque nos parecía absurda e inexplicable o atrevida e incluso vanguardista?" (Diego Otero 1995: 92).

Es cierto que en la sociedad actual se tiende a utilizar el término "surrealista" de una manera muy vaga e inexacta, usándose para describir situaciones extravagantes. Sin embargo, una situación surrealista puede ser extravagante, sin que el término se refiera a algo que está fuera de lo común, sino a aquello que nace de un automatismo psíquico.

En este punto podemos encontrar situaciones que son surrealistas y no extravagantes, como 
todas aquellas decisiones que las personas tomamos desde lo emocional y no desde lo racional; cosas que "hacemos sin pensar" en momentos que nos dejamos llevar por la intuición o por un sentimiento repentino. Esto también implica que el ser surrealista o ver/tener una situación surrealista tampoco sea tan extraordinario como normalmente se suele pensar. Tomado como conducta o como pose, es lo que llamamos surrealismo en sentido estricto, lo cual podemos relacionar claramente con la figura de Salvador Dalí:

Aparentemente, Dalí es un pintor que no ofrece demasiados problemas a la hora de ser etiquetado, porque él mismo se prestó de buen grado a la conversión de su nombre en un membrete trasladable a camisas, joyas, diseños de botellas, perfumes y todo tipo de pret à porter y pret à penser. Ello ha facilitado enormemente su adscripción a un marchamo, el de «surrealista», que gracias a él -o por su culpa- se ha convertido en sinónimo de «estrambótico», «estrafalario», y a la vez en algo apto para ser exhibido en las fiestas de sociedad convocadas por la internacional del snobismo. (Sánchez Vidal 2002: 162)

Un hecho diferente es que Breton le adjudicase esa característica a personas que no eran surrealistas por capricho, aprovechándose de su condición de cabeza visible del movimiento, o que encontremos artistas que toman prestadas algunas características estéticas del Surrealismo. ¿Pero cuántos de esos miembros señalados por Breton se adhirieron a las normas del movimiento como a una confesión personal?

Por otra parte, no debemos perder de vista las propias ideas que Maruja Mallo tenía sobre el Surrealismo en 1936:

El surrealismo, movimiento, literario, no añade a la plástica ningún hallazgo técnico, es una pintura de narraciones incoherentes. El surrealismo son los últimos sobresaltos de una época de agonía; es una protesta anárquica pasiva y literaria. (Rodríguez Calatayud 2007: 535-537)

En primer lugar, Maruja Mallo nos recuerda que el Surrealismo nació como movimiento literario, no plástico, y nos lo diferencia de otros movimientos plásticos que sí tuvieron una incidencia importante en la técnica artística, como es el Cubismo. Llama la atención el desprecio con el que habla del Surrealismo, tachándolo de incoherente, anárquico, pasivo... incluso el término literario parece peyorativo en este contexto.

No obstante, encontramos también en la historiografía opiniones a favor de una visión surrealista de Maruja Mallo -aunque sea parcial- como expone la profesora García de Carpi:

La confusión entre las cualidades físicas de los objetos y los productos de la imaginación es una vía más en el proceso de desrealización del mundo al que aspiran los surrealistas. Lo real y lo imaginario rompen sus límites, para dar paso a una realidad diferente, la surrealidad, en la que nada se halla sujeto a la lógica. (1986: 170)

Cabría preguntarse si todos los artistas que representaban con mucha verosimilitud realidades imposibles tenían la intención de dar paso a un mundo diferente. Es más probable que dentro de este grupo de artistas que pintan realidades con significados inconexos se encontraran aquellos que efectivamente tomaron como filosofía de vida crear un mundo diferente basado en una lucha sin cuartel contra la razón, pero también es más que factible que hubiera artistas que tomaran estos rasgos superficiales y no siguieran a Breton ni a pies juntillas, ni de ninguna otra manera. $Y$ eso evidentemente no lo decidía Breton, sino que cada cual con su actitud se definía como surrealista o no. En este punto me gustaría volver al texto de la profesora De Diego, porque aporta ideas que pueden resolver la cuestión, en relación al cartel de Camaret: "En el caso de Mallo, el poeta no trabaja, calcula. Entonces, si el poeta calcula, ¿por qué se le llamó surrealista?" (1995: 80).

Claro que Maruja Mallo piensa, y piensa hasta el punto de calcular los pasos que va dando. ¿Qué clase de surrealista haría eso? ¿Quién entre los surrealistas se dedicaría a medir con un compás las caracolas y las conchas arrojadas por el mar para después llevarlo al lienzo (figura 7)? ¿Qué surrealista dejaría a Freud por Luca Pacioli y por Ghyka?

No considero que Maruja Mallo responda a los arquetipos surrealistas, porque nuestra artista no se deja llevar por los automatismos, ni su voluntad es la de crear un mundo mejor a través de su pintura. Por el contrario, su obra siempre tuvo mensaje: más claro o más oscuro, pero lo tuvo. Tampoco creo que su vinculación con los grandes personajes del grupo surrealista sea lo suficientemente representativa para poder adscribirla al mismo, porque Maruja es esa especie de rara avis que puede participar de varias sensibilidades sin perder su propia voz, que es lo que esti- 
mo que debemos valorar sobre todas las cosas.

Nos basta con comparar su obra con la de autores considerados plenamente surrealistas como Tanguy o Max Ernst, o con Dalí o Magritte si queremos llevarlo a un terreno figurativo; pero no es necesario que haya que complicarlo más, porque ella misma revela sus verdaderas intenciones en la primera entrevista que hace en Buenos Aires en 1939: "[...] un orden rige el universo y una misma ley impera en el astro, en el copo, en el ser, en la flor y en la semilla. Sabe que esta ley es la ley del número, la ley que impone la proporción y el equilibrio" (Rodríguez Calatayud 2007: 524-530).

Maruja Mallo es orden, es geometría, es ciencia, es número, y si alguna vez fue surrealista, ella misma se encargó de enterrarlo para siempre denominándolo "improvisación y barroquismo" (Rodríguez Calatayud 2007: 524-530), hablando de ello como una primera etapa más que superada.

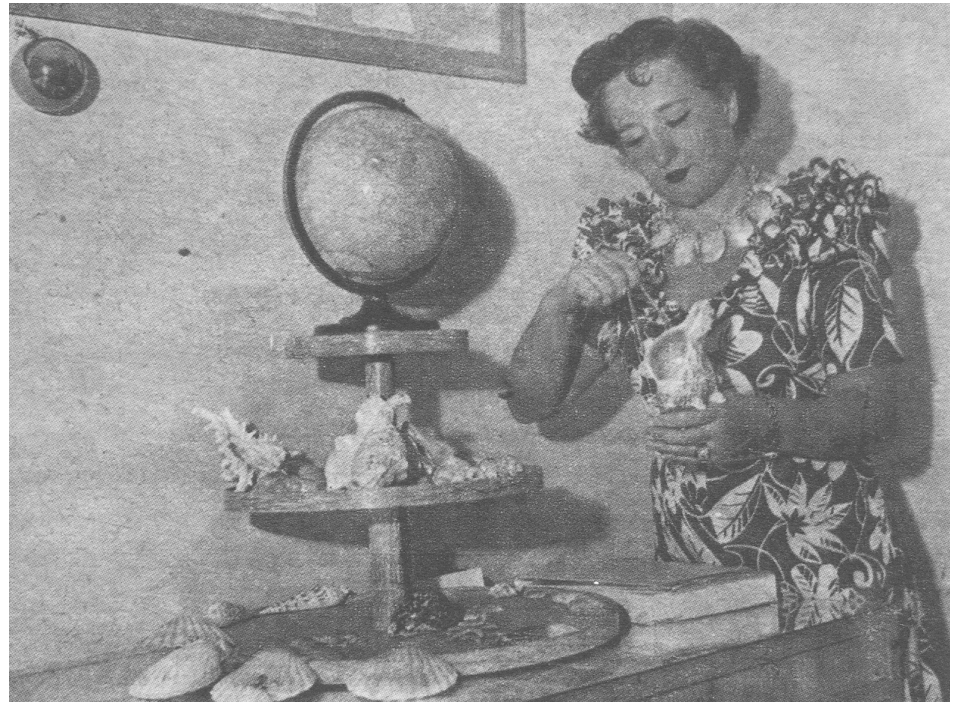

Figura 7. Maruja Mallo midiendo una caracola, Buenos Aires, 1944 (Pérez de Ayala 2002b: 16).

\section{REFERENCIAS BIBLIOGRÁFICAS}

Amón, Santiago y Bonet, Juan Manuel (1977): “Entrevista con Maruja Mallo”, El País (30/01/1977), Madrid.

CARABias, Josefina (1931): "La pintora Maruja Mallo marcha a París", Estampa, no 201, año IV $(14 / 11 / 1931)$, Madrid

Diego Otero, Estrella de (1995): "María, Maruja, Mallo", Revista de Occidente, no 168, pp. 77-92, Madrid.

(2008): Maruja Mallo. Madrid: Fundación Cultural Mapfre Vida.

FerRIs, José Luis (2004): Maruja Mallo. La gran transgresora del 27. Madrid: Temas de Hoy.

ForNeT, Emilio (1934): “Maruja Mallo, o la imaginación”, Estampa, no 324, Año VII (24/03/1934), Madrid.

GALDO, Fausto (1992): Pintura y pintores de Viveiro. Sada (A Coruña): Ediciós do Castro.

GÁnDARA, Consuelo de la (1976): "Maruja Mallo", Cuadernos Hispanoamericanos, no 310, pp. 5-17, Madrid.

GARCíA DE CARPI, Lucía (1986): La pintura surrealista española (1924-1936). Madrid: Ed. Istmo.

JIMÉNEZ, Juan Ramón (1931): “Acento. Historias de España. Evolución superinocente. Satanismo inverso", La Gaceta Literaria (15/01/1931), Madrid. 
LÓPEZ LóPEz, Yolanda (2002): "Maruja Mallo: O soño e a recreación submarina", Madrygal. Revista de Estudios Gallegos, $\mathrm{n}^{\circ}$ 5, pp. 81-84, Madrid.

Neruda, Pablo (1974): Confieso que he vivido. Memorias. Barcelona: Seix-Barral.

Ortega, Soledad (1995): "Recuerdo de Maruja Mallo", Revista de Occidente, no 168, pp. 75-76, Madrid.

PÉREZ De Ayala, Juan (2002a): "Maruja Mallo", en Valeriano Bozal (coord.), Creadores del Arte Nuevo. Madrid: Fundación Cultural Mapfre Vida, pp. 372 y 387.

PÉREZ DE AyAla, Juan (2002b): Naturalezas vivas: 1941-1944. Madrid: Guillermo García de Osma.

Pérez Febrero, Miguel (1928): "Baraja de estampas", Revista Avance, pp. 220-222, La Habana.

Rodríguez Calatayud, M. N. (2007): Archivo y memoria femenina. Los textos de la mujer artista durante las primeras vanguardias (1900-1945). Tesis doctoral (dir. L. Armand Buendía).

SÁnchez VIDAL, Agustín (2002): "El joven Dalí: El nido de la urraca", en Valeriano Bozal (coord.), Creadores del Arte Nuevo. Madrid: Fundación Cultural Mapfre Vida.

VAldeAVEllano, Luis G. de (1927): “Maruja Mallo en su carrousel”, La Gaceta Literaria (01/09/1927), Madrid. 